\title{
BMJ Open Association between body height and chronic low back pain: a follow-up in the Nord-Trøndelag Health Study
}

\author{
Ingrid Heuch, ${ }^{1}$ Ivar Heuch, ${ }^{2}$ Knut Hagen, ${ }^{3,4}$ John-Anker Zwart ${ }^{1,5}$
}

To cite: Heuch I, Heuch I, Hagen $\mathrm{K}$, et al. Association between body height and chronic low back pain: a follow-up in the NordTrøndelag Health Study. BMJ Open 2015;5:e006983. doi:10.1136/bmjopen-2014006983

- Prepublication history and additional material is available. To view please visit the journal (http://dx.doi.org/ 10.1136/bmjopen-2014006983).

Received 22 October 2014 Revised 19 May 2015 Accepted 21 May 2015

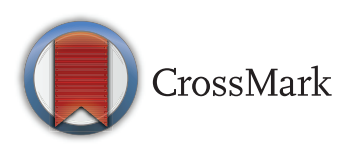

${ }^{1}$ Department of Neurology and FORMI, Oslo University Hospital, Oslo, Norway

${ }^{2}$ Department of Mathematics, University of Bergen, Bergen, Norway

${ }^{3}$ Department of Neuroscience, Norwegian University of Science and Technology, Trondheim, Norway

${ }^{4}$ Department of Neurology, Norwegian National Headache Centre, St Olavs Hospital, Trondheim, Norway

${ }^{5}$ Faculty of Medicine, University of Oslo, Oslo, Norway

Correspondence to Dr Ingrid Heuch; ingrid.heuch@ous-hf.no

\section{ABSTRACT}

Objective: To study potential associations between body height and subsequent occurrence of chronic low back pain (LBP).

Design: Prospective cohort study.

Setting: The North-Trøndelag Health Study (HUNT). Data were obtained from a whole Norwegian county in the HUNT2 (1995-1997) and HUNT3 (2006-2008) surveys.

Participants: Altogether, 3883 women and 2662 men with LBP, and 10059 women and 8725 men without LBP, aged 30-69 years, were included at baseline and reported after 11 years whether they suffered from LBP.

Main outcome measure: Chronic LBP, defined as pain persisting for 3 months during the previous year.

Results: Associations between body height and risk and recurrence of $L B P$ were evaluated by generalised linear modelling. Potential confounders, such as BMI, age, education, employment, physical activity, smoking, blood pressure and lipid levels were adjusted for. In women with no LBP at baseline and body height $\geq 170 \mathrm{~cm}, \mathrm{a}$ higher risk of LBP was demonstrated after adjustment for other risk factors (relative risk $1.19,95 \% \mathrm{Cl} 1.03$ to 1.37 ; compared with height $<160 \mathrm{~cm}$ ). No relationship was established among men or among women with LBP at baseline.

Conclusions: In women without LBP, a body height $\geq 170 \mathrm{~cm}$ may predispose to chronic LBP 11 years later. This may reflect mechanical issues or indicate a hormonal influence.

\section{INTRODUCTION}

Chronic low back pain (LBP) is a common disorder that has been associated with several predisposing factors. It has been difficult to identify the cause of non-specific LBP, and the onset of pain is most likely due to a complex interaction between environmental and genetic factors. It has been shown that a large body mass index (BMI) predisposes to LBP, ${ }^{12}$ but the association between body height and LBP has not been studied extensively. Body height is most likely influenced by genetic disposition, but circumstances during fetal development or in childhood, malnutrition,

\section{Strengths and limitations of this study}

- The study provides new information about risk factors for non-specific low back pain (LBP), a condition that has few obvious causes.

- The association between body height and chronic LBP was studied in an 11-year population-based follow-up study of a large cohort in Norway.

- Information available on potential confounders made it possible to carry out accurate adjustment.

- A limitation of the study is the lack of information about back pain occurring at other times in the 11-year follow-up interval.

previous diseases and psychosocial factors are also important. ${ }^{3}$ In women, a large body height is associated with increased risk of several diseases, such as cancer of the ovaries $^{4}{ }^{5}$ and breast. ${ }^{5}$ By contrast, coronary artery disease is associated with short height. ${ }^{6}$

Earlier studies have shown conflicting evidence on the potential association between body height and LBP, and whether there are gender differences, but it is not clear whether all studies adjusted properly for BMI or body weight. Thus, body height has been found to be positively associated with the prevalence of LBP in both genders in young people. ${ }^{7}$ However, in a population study of adults over a 40-year age span, the risk of LBP was increased among tall men, but was not associated with body height among women. ${ }^{8}$

Although adult body height is hardly a factor that can be influenced, it is important to look at this variable for understanding the interplay between risk factors in explaining the causes of LBP. In this study, we consider the effect of body height on the development of LBP among adults, in an 11-year follow-up study based on data from two large health surveys in Norway.

\section{METHODS}

Participants

The health survey, the North-Trøndelag Health Study (HUNT) 2 was carried out in 
Nord-Trøndelag County from 1995 to 1997, with a participation rate of $69 \% .^{9}$ The HUNT3 health survey was carried out from 2006 to 2008 in the same county with a similar target population. ${ }^{10}$ Participants underwent a clinical examination, had blood samples taken and filled in a questionnaire indicating whether they experienced LBP lasting for at least 3 months continuously during the past year, which was regarded as chronic LBP. The present follow-up study was based on baseline information from HUNT2 about chronic LBP and potential risk factors, linked to information about chronic LBP collected in the subsequent HUNT3 survey.

The study was aimed at a cohort consisting of 44647 individuals who were 30-69 years old when they participated in the HUNT2 survey, with information available on anthropometric measures and presence or absence of chronic LBP (figure 1). During the period of follow-up from HUNT2 to HUNT3, 2631 persons in this cohort died and 1675 persons left the county. The flow chart (figure 1) shows the corresponding numbers according to LBP status at baseline. Furthermore, 15012 members of the cohort residing in Nord-Trøndelag during HUNT3 did not participate at the end of follow-up, or did not supply information about LBP. Thus, a total of 25329 persons, 13942 women and 11387 men, were available for analysis (figure 1), representing $62.8 \%$ of the remaining individuals resident in the county.

\section{Exposure and covariate assessment}

Height and weight were measured with the participants wearing light clothes and without shoes; height to the nearest $1.0 \mathrm{~cm}$, and weight to the nearest $0.5 \mathrm{~kg}$. Body height was categorised into four groups: $<160,160-164$, $165-169, \geq 170 \mathrm{~cm}$ for women and $<175,175-179,180$ $184, \geq 185 \mathrm{~cm}$ for men. BMI, defined as weight $/$ height $^{2}$ and computed in $\mathrm{kg} / \mathrm{m}^{2}$, was subdivided into three groups: $<25,25-29.9, \geq 30$.

Information on physical activity in leisure time, including going to and returning from work, was self-reported. One item in the questionnaire referred to light activity only, defined as activity that did not lead to sweating or breathlessness and another item involved hard physical activity, leading to participants sweating or being out of breath. In the present study, three levels of physical activity were considered, the low level representing light physical activity only or hard physical activity less than

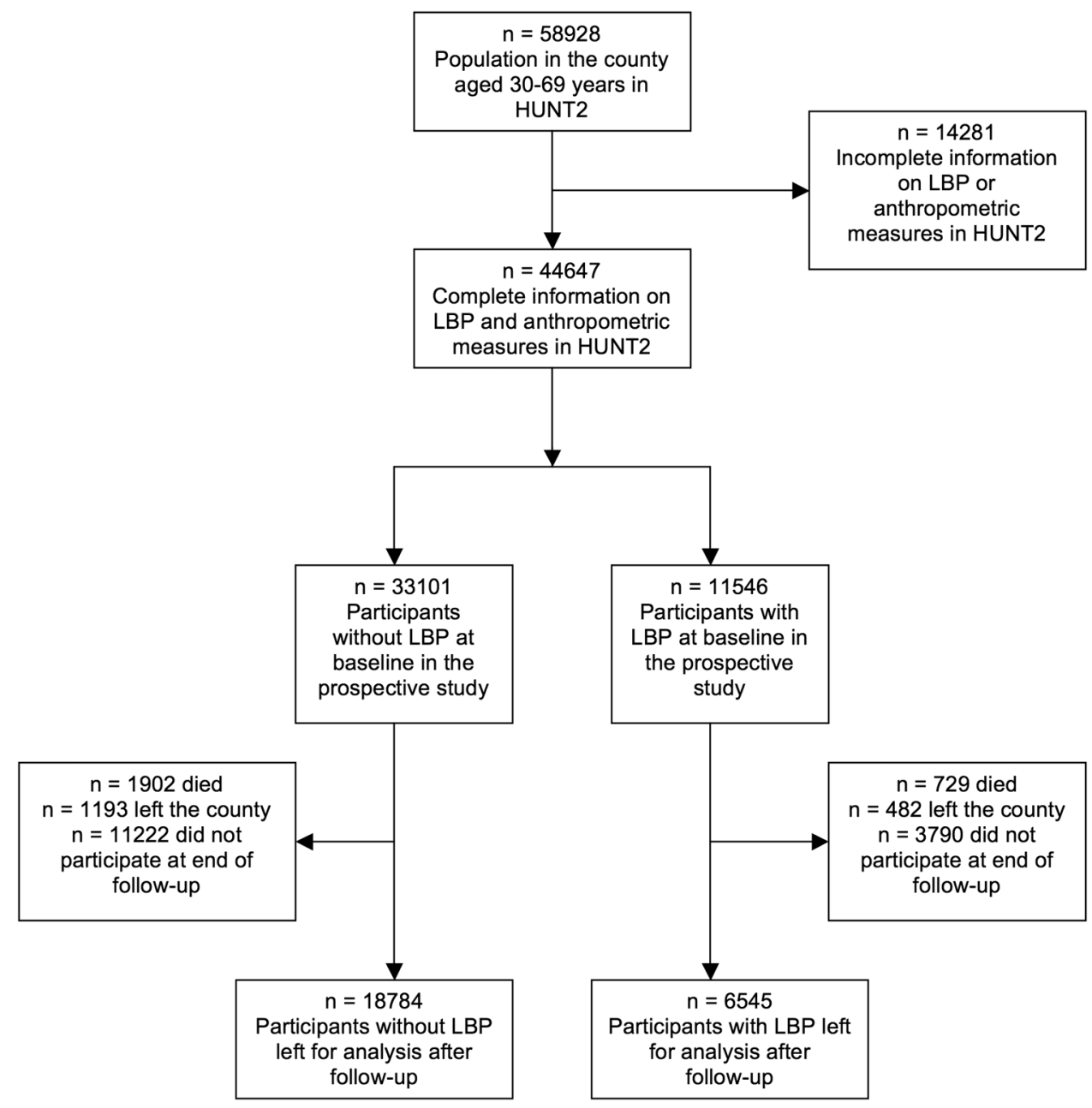

Figure 1 Flow chart showing the cohort considered, and loss during follow-up. HUNT, North-Trøndelag Health Study; LBP, low back pain. 
$1 \mathrm{~h} /$ week, the medium level representing hard physical activity 1-2 $\mathrm{h} /$ week, and the high level representing hard physical activity at least $3 \mathrm{~h} /$ week.

Respondents currently working also provided information about physical activity at work in four categories. The first category represented sedentary work (eg, assembly or desk work), the second group involved walking but no heavy lifting (eg, light manufacturing, sales people or teachers), the third category involved both walking and lifting (eg, postmen, nurses or construction workers) and the fourth group represented particularly strenuous physical work (people practising heavy agricultural or forestry work and heavy construction work). Other separate categories included people temporarily out of work (eg, students and those in military service), and people receiving social security support (eg, disabled and old-age pensioners), with no further subdivision according to physical activity. A separate category was also defined for full-time housewives.

Education was categorised according to the number of years, $\leq 9,10-12$ or $\geq 13$ years. Categories of cigarette smoking corresponded to never, former and current smokers. Systolic blood pressure was categorised as $<120$, $120-139,140-159$ and $\geq 160 \mathrm{~mm} \mathrm{Hg}$ and diastolic blood pressure as $<80,80-89,90-99$ and $\geq 100 \mathrm{~mm} \mathrm{Hg}$. Levels of HDL cholesterol and triglycerides in non-fasting blood were measured by enzymatic colorimetric procedures and were categorised by quintiles. ${ }^{11}$ Age at baseline was categorised in 10-year intervals.

\section{Statistical methods}

Generalised linear modelling for binomially distributed data with a $\log$ link and adjustment for potential risk factors was used to evaluate associations between height, and risk and recurrence of LBP. Since LBP is a common disorder, this procedure was chosen in preference to logistic regression, which might produce estimates of ORs that are not good approximations to relative risks
(RR). Analyses were performed separately with height as a categorical and continuous variable. All other covariates were regarded as categorical in the risk analysis. A test for deviation from linearity in continuous height was performed by including an additional quadratic term in the regression. Statistical analyses were carried out using IBM SPSS V.19.

\section{RESULTS}

Among participants included in the analysis who did not report chronic LBP at baseline, a total of 10059 women and 8725 men, altogether 2006 women and 1224 men experienced chronic LBP at the end of follow-up. Among participants in the analysis who reported chronic LBP at baseline, a total of 3883 women and 2662 men, altogether 2319 women and 1269 men experienced chronic LBP at the end of follow-up (table 1). Online supplementary tables S1 and S2 describe the distributions of covariates among women without LBP at baseline and online supplementary tables S3 and S4 describe the corresponding distributions among men.

The risk of LBP increased with increasing body height among women not suffering from LBP at baseline (table 1). No definite tendency was found among men without LBP at baseline, but the highest risk was seen among men $\geq 185 \mathrm{~cm}$. No clear tendencies could be found among women or men who experienced LBP at baseline.

Among women without LBP at baseline, a weak positive association between body height and LBP was suggested with adjustment for age only, with very similar results after additional adjustment for BMI (table 2). With complete adjustment, the association became stronger and statistically significant (RR per $10 \mathrm{~cm} 1.09$ (95\% CI 1.01 to 1.17$)$ ). Risk estimates increased gradually along with increasing categories of height (table 2). There was no significant deviation from

Table 1 Crude risk and recurrence of LBP by height at baseline

\begin{tabular}{|c|c|c|c|c|}
\hline & \multicolumn{2}{|c|}{$\begin{array}{l}\text { Risk among persons without } \\
\text { LBP at baseline }\end{array}$} & \multicolumn{2}{|c|}{$\begin{array}{l}\text { Recurrence among persons } \\
\text { with LBP at baseline }\end{array}$} \\
\hline & Total & $\begin{array}{l}\text { With LBP at end } \\
\text { of follow-up (\%) }\end{array}$ & Total & $\begin{array}{l}\text { With LBP at end } \\
\text { of follow-up (\%) }\end{array}$ \\
\hline \multicolumn{5}{|l|}{ Women } \\
\hline \multicolumn{5}{|l|}{ Height $(\mathrm{cm})$} \\
\hline$<160$ & 1748 & 335 (19.2) & 692 & $414(59.8)$ \\
\hline $160-164$ & 3035 & $600(19.8)$ & 1201 & $720(60.0)$ \\
\hline $165-169$ & 3220 & 652 (20.2) & 1179 & 683 (57.9) \\
\hline$\geq 170$ & 2056 & 419 (20.4) & 811 & 502 (61.9) \\
\hline \multicolumn{5}{|l|}{ Men } \\
\hline \multicolumn{5}{|l|}{ Height (cm) } \\
\hline$<175$ & 2453 & $343(14.0)$ & 811 & $389(48.0)$ \\
\hline $175-179$ & 2627 & 354 (13.5) & 74 & 383 (49.5) \\
\hline $180-184$ & 2224 & 302 (13.6) & 691 & 326 (47.2) \\
\hline$\geq 185$ & 1421 & 225 (15.8) & 386 & 171 (44.3) \\
\hline
\end{tabular}


Table 2 Associations between height and risk of LBP, among individuals without LBP at baseline

\begin{tabular}{|c|c|c|c|}
\hline & $\begin{array}{l}\text { Risk ratio }(95 \% \mathrm{Cl}) \\
\text { With adjustment for age }\end{array}$ & $\begin{array}{l}\text { Risk ratio }(95 \% \mathrm{Cl}) \\
\text { With adjustment for age and } \mathrm{BMI}\end{array}$ & $\begin{array}{l}\text { Risk ratio }(95 \% \mathrm{Cl}) \\
\text { With complete adjustment }{ }^{*}\end{array}$ \\
\hline \multicolumn{4}{|l|}{ Women } \\
\hline$<160$ & 1.00 (Reference) & 1.00 (Reference) & 1.00 (Reference) \\
\hline $160-164$ & $1.04(0.92$ to 1.17$)$ & $1.03(0.92$ to 1.17$)$ & $1.09(0.95$ to 1.24$)$ \\
\hline Per $10 \mathrm{~cm} \ddagger$ & $1.03(0.96$ to 1.10$)$ & $1.04(0.97$ to 1.11$)$ & 1.09 (1.01 to 1.17$)$ \\
\hline $\mathrm{p}$ For trend $\ddagger$ & 0.45 & 0.32 & 0.03 \\
\hline \multicolumn{4}{|l|}{ Men } \\
\hline \multicolumn{4}{|l|}{ Height $(\mathrm{cm})$} \\
\hline$<175$ & 1.00 (Reference) & 1.00 (Reference) & 1.00 (Reference) \\
\hline$\overline{P e r} 10 \mathrm{~cm} \ddagger$ & $1.01(0.93$ to 1.10$)$ & $1.02(0.94$ to 1.11$)$ & $1.04(0.96$ to 1.14$)$ \\
\hline $\mathrm{p}$ For trend $\neq$ & 0.82 & 0.61 & 0.33 \\
\hline
\end{tabular}

linearity $(p=0.48)$. Among men, no significant associations with body height were seen, even after complete adjustment. Nevertheless, in the group of the tallest men, the risk estimate was increased, especially with complete adjustment.

Table 3 shows results from the continuous analyses within categories of age and BMI at baseline. No significant differences were observed between effects in age groups or categories defined by BMI. The risk ratios for women suggested positive associations within each age category and within each category of BMI. For men, modest positive associations were suggested in the lowest groups of age. In men with BMI $\geq 30$, a more pronounced positive association was found. The overall analyses were also carried out with more detailed adjustment for BMI in five categories, and the results were essentially unchanged.

Among those suffering from LBP at baseline, no linear relations were found between height and recurrence of LBP after 11 years, either among women (RR per $10 \mathrm{~cm} 1.04(95 \%$ CI 0.99 to 1.09$)$ ) or men (RR per $10 \mathrm{~cm} 0.95$ (95\% CI 0.89 to 1.02$)$ ).

Table 3 Associations between height and risk of LBP among individuals without LBP at baseline, by age and BMI

\begin{tabular}{|c|c|c|c|c|}
\hline & \multicolumn{2}{|l|}{ Women } & \multicolumn{2}{|l|}{ Men } \\
\hline & Total included & $\begin{array}{l}\text { Risk ratio }(95 \% \mathrm{Cl}) \\
\text { per } 10 \mathrm{~cm}^{\star}\end{array}$ & Total included & $\begin{array}{l}\text { Risk ratio }(95 \% \mathrm{Cl}) \\
\text { per } 10 \mathrm{~cm}^{\star}\end{array}$ \\
\hline \multicolumn{5}{|l|}{ Age at baseline (years) } \\
\hline 30-39 & 2558 & $1.12(0.97$ to 1.28$)$ & 1987 & $1.11(0.94$ to 1.31$)$ \\
\hline $40-49$ & 3072 & $1.03(0.91$ to 1.17$)$ & 2749 & $1.11(0.96$ to 1.28$)$ \\
\hline $50-59$ & 2239 & $1.10(0.94$ to 1.29$)$ & 2201 & $0.91(0.76$ to 1.09$)$ \\
\hline $60-69$ & 1234 & $1.17(0.95$ to 1.45$)$ & 1164 & $0.98(0.76$ to 1.27$)$ \\
\hline $\begin{array}{l}\text { p For interaction between height and age } \dagger \\
\text { BMl }\left(\mathrm{kg} / \mathrm{m}^{2}\right)\end{array}$ & & 0.72 & & 0.40 \\
\hline$<25$ & 4431 & 1.09 (0.98 to 1.22$)$ & 2660 & $1.00(0.85$ to 1.17$)$ \\
\hline $25-29.9$ & 3421 & 1.07 (0.95 to 1.21$)$ & 4422 & $1.04(0.92$ to 1.17$)$ \\
\hline$\geq 30$ & 1251 & $1.13(0.93$ to 1.37$)$ & 1019 & $1.17(0.95$ to 1.44$)$ \\
\hline $\mathrm{p}$ For interaction between height and BMI† & & 0.86 & & 0.46 \\
\hline
\end{tabular}




\section{DISCUSSION}

In this large population-based 11-year follow-up study, an association between body height and LBP was found in women without LBP at baseline, within the ordinary limits of uncertainty set by statistical procedures. Adjustment for BMI had hardly any influence on the association that was observed in women with high as well as low BMI at start of follow-up. It is therefore unlikely that the association with body height could be caused by an effect of increased body weight among tall women. Overall adjustment for other risk factors was still essential for detecting the relationship with body height. The magnitude of the association was modest. For example, for a woman $180 \mathrm{~cm}$ tall compared to the population average of $165 \mathrm{~cm}$ (see online supplementary table S1), the model based on height as a continuous variable predicts a $14 \%$ increase in risk. However, only $0.6 \%$ of the female population had a height of $180 \mathrm{~cm}$ or more, so for the great majority of women the increase is of minor concern.

On the basis of our data, it is not possible to infer that body height in men influences the risk of subsequent LBP. The width of the CIs determined makes it unlikely, however, that any real association is very strong. Our results are still consistent with an increased risk of LBP among men who are $185 \mathrm{~cm}$ or taller.

A strength of this study is the follow-up over a long period of time with a large number of participants recruited from an entire county. Measurements of height and weight were probably quite accurate. Although response rates were relatively high in the HUNT2 survey, the response was lower in the subsequent HUNT3 survey, and part of our cohort was lost during follow-up. We could not demonstrate that participation was substantially different in any particular group of body height, but participants without LBP at baseline subsequently lost to follow-up had somewhat higher systolic blood pressure, experienced less physical activity, were more often smokers and had less education (see online supplementary tables S1-S4). The same tendencies were found among participants with baseline LBP (results not shown).

One limitation of this study is the reliance on the information on pain collected in the questionnaires at baseline and at the end of follow-up. No further information was available about the medical history of back pain in each respondent, or about pain occurring in the intervening 11-year period. No detailed check of back status was made at the clinical examinations, and the pain intensity was not recorded. Some participants may have suffered from disc degeneration or herniation, or from osteoporosis or fractures and some may have experienced LBP as part of other conditions such as malignant disorders or inflammatory joint disease. ${ }^{12}$ Although no age interaction was demonstrated in this study, the participants displayed substantial age differences, which makes it likely that the LBP recorded has many different sources. ${ }^{13}$ Thus, it is difficult to say whether the association observed with height among women represents a stronger, more specific relationship with a particular subgroup of the LBP cases, or if it simply reflects a general weak relationship.

It is not clear whether all previous studies of associations between body height and LBP were carried out with sufficient adjustment. An extensive cross-sectional study of Israeli military recruits found body height to be positively associated with the prevalence of LBP in both sexes, ${ }^{7}$ with ORs of 1.8 and 2.1 comparing extreme quintiles in women and men. However, adjustment was not possible for many potential risk factors. In a relatively large cross-sectional study from the Netherlands, ${ }^{14}$ an inverse association largely disappeared after adjustment for age, smoking and education. In a cross-sectional Japanese study of those who worked sitting down, those who were at least $170 \mathrm{~cm}$ tall carried a RR of about 1.4 compared to those who were $160-169 \mathrm{~cm} .{ }^{15}$ In a British retrospective study of lifetime risk of LBP, men with a height of $184 \mathrm{~cm}$ or more had double the risk of those who were $170 \mathrm{~cm}$ or shorter. ${ }^{8}$ No association was seen among women. A British 1-year follow-up study of general practice populations found no clear evidence of an association in either gender. ${ }^{16}$ Height more than $180 \mathrm{~cm}$ was a risk factor for sciatica, but not for LBP without sciatica, in a 2-year follow-up of French men. ${ }^{17}$ In a large Finnish population-based follow-up study, a body height of at least $180 \mathrm{~cm}$ for men and $170 \mathrm{~cm}$ for women was a predictor of being diagnosed with herniated lumbar intervertebral discs. ${ }^{18}$ Another Finnish study also showed greater body height among patients undergoing surgery for disc herniation. ${ }^{19}$ In a large French prospective study, being tall $(\geq 178 \mathrm{~cm})$ was a predictor for back surgery among men. ${ }^{20}$

The overall impression of the existing evidence is that most data sets either support a positive association between body height and risk of LBP, or that essentially no association could be established. In some cases, the associations reported seem remarkably strong in comparison with our estimates. Some discrepancies may be caused by different adjustment for other risk factors. In view of the relatively strong association between BMI and risk of LBP, ${ }^{12}$ adjustment for body size may be particularly important. Some apparent inconsistencies may also be due to different study designs, although LBP, the disorder under study, would hardly be expected to affect body height, so cross-sectional studies should be fairly reliable. It is also possible that publication bias may have affected studies finding weak or no associations with height, so that studies reporting strong relationships are over-represented in the literature.

By contrast with results concerning the association between BMI and LBP, our findings have no essential implications for clinical work or for public health. As the aetiology of this common disorder is largely unknown, it is still essential to investigate potential relationships with readily measurable risk factors such as height. Both the positive association with BMI and the weak association seen 
with height among women in this study indicate that a large body size, overall, may increase the total risk of LBP.

There is no obvious causal explanation for the association observed in women between LBP and body height, although tall people may be exposed to other mechanical issues, both anatomical and stress-related. There are indications that growth in adolescence may be related to LBP at a young age. ${ }^{21} \mathrm{~A}$ correlation between body height and facet joint asymmetry in patients with disc herniation has been reported. ${ }^{22}$ Social factors are significant for both height ${ }^{23}$ and LBP. For other diseases with established associations with body height, as for certain cancers, the explanatory mechanisms have not been clarified. Hormonal factors may be significant, perhaps in relation to gender differences. The inverse association between height and coronary artery disease has partly been explained by an adverse lipid profile in short people, ${ }^{6}$ but this explanation seems less relevant for a positive association such as that observed with LBP, and, in any case, relationships between lipid levels and risk of LBP are not very strong. ${ }^{11}$ Future studies of LBP in adulthood should also take into account data on the development of body height in childhood and adolescence.

\section{CONCLUSIONS}

In this large population-based study, we found that women with body height of at least $170 \mathrm{~cm}$, who did not experience LBP at baseline, had 19\% increased risk of LBP compared to women with body height less than $160 \mathrm{~cm}$. This may reflect mechanical issues or indicate a hormonal influence.

Acknowledgements The Nord-Trøndelag Health Study (the HUNT study) is a collaboration between the HUNT Research Centre, Faculty of Medicine, the Norwegian University of Science and Technology (NTNU); Norwegian Institute of Public Health; and the Nord-Trøndelag County Council. Laboratory measurements were carried out at facilities owned by the Nord-Trøndelag Hospital Trust.

Contributors $\mathrm{InH}$ and IvH contributed to study conception and design. $\mathrm{KH}$ and J-AZ contributed to acquisition of data. InH, IvH, KH and J-AZ contributed to analysis and interpretation of data. All authors were involved in drafting the article and revising it critically for important intellectual content, and all authors approved the final version to be submitted for publication.

Funding This study was supported in part by grants from the legacy of Trygve Gythfeldt and his Wife.

\section{Competing interests None declared.}

Ethics approval The work was approved by the The Regional Committees for Medical and Health Research Ethics, and HUNT was also approved by the Norwegian Data Protection Authority.

\section{Provenance and peer review Not commissioned; externally peer reviewed.}

Data sharing statement The data set that is analysed belongs to a third party, the HUNT study (the Nord Trøndelag Health Study). The authors of the current manuscript are not affiliated with the project as such, but have been given permission to analyse the data after obtaining the necessary Norwegian permits. It is very doubtful whether a data set of this kind with information from a complete county at the individual level can be made public. This is because of the confidentiality requirements according to Norwegian law. However, research groups wishing to analyse data from the HUNT study may apply to the HUNT organisation (http://www.ntnu.edu/hunt) to get access to the data, after having obtained the permits needed according to Norwegian law.
Open Access This is an Open Access article distributed in accordance with the Creative Commons Attribution Non Commercial (CC BY-NC 4.0) license, which permits others to distribute, remix, adapt, build upon this work noncommercially, and license their derivative works on different terms, provided the original work is properly cited and the use is non-commercial. See: http:// creativecommons.org/licenses/by-nc/4.0/

\section{REFERENCES}

1. Shiri R, Karppinen J, Leino-Arjas $\mathrm{P}$, et al. The association between obesity and low back pain: a meta-analysis. Am J Epidemiol 2010;171:135-54.

2. Heuch I, Heuch I, Hagen K, et al. Body mass index as a risk factor for developing chronic low back pain: a follow-up in the Nord-Trøndelag Health Study. Spine (Phila Pa 1976) 2013:38:133-9.

3. Shen T, Habicht JP, Chang Y. Effect of economic reforms on child growth in urban and rural areas of China. N Engl J Med 1996;335:400-6.

4. Schouten LJ, Rivera C, Hunter DJ, et al. Height, body mass index, and ovarian cancer: a pooled analysis of 12 cohort studies. Cancer Epidemiol Biomarkers Prev 2008;17:902-12.

5. Lundqvist E, Kaprio J, Verkasalo PK, et al. Co-twin control and cohort analyses of body mass index and height in relation to breast, prostate, ovarian, corpus uteri, colon and rectal cancer among Swedish and Finnish twins. Int J Cancer 2007:121:810-18.

6. Nelson CP, Hamby SE, Saleheen D, et al. Genetically determined height and coronary artery disease. N Engl J Med 2015;372:1608-18.

7. Hershkovich O, Friedlander A, Gordon B, et al. Associations of body mass index and body height with low back pain in 829,791 adolescents. Am J Epidemiol 2013;178:603-9.

8. Walsh K, Cruddas M, Coggon D. Interaction of height and mechanical loading of the spine in the development of low-back pain. Scand J Work Environ Health 1991;17:420-4.

9. Holmen J, Midthjell K, Krüger $\varnothing$, et al. The Nord-Trøndelag Health Study 1995-97 (HUNT 2): objectives, contents, methods and participation. Nor Epidemiol 2003;13:19-32.

10. Krokstad S, Langhammer A, Hveem K, et al. Cohort profile: the HUNT Study, Norway. Int J Epidemiol 2013;42:968-77.

11. Heuch I, Heuch I, Hagen K, et al. Do abnormal serum lipid levels increase the risk of chronic low back pain? The Nord-Trøndelag Health Study. PLoS ONE 2014;9:e108227.

12. Van Hoeven L, Luime $\mathrm{J}$, Han $\mathrm{H}$, et al. Identifying axial spondyloarthritis in Dutch primary care patients, ages $20-45$ years, with chronic low back pain. Arthritis Care Res (Hoboken) 2014:66:446-53.

13. DePalma MJ, Ketchum JM, Saullo T. What is the source of chronic low back pain and does age play a role? Pain Med 2011;12:224-33.

14. Han TS, Schouten JSAG, Lean MEJ, et al. The prevalence of low back pain and associations with body fatness, fat distribution and height. Int J Obes 1997;21:600-7.

15. Inoue G, Miyagi M, Uchida $\mathrm{K}$, et al. The prevalence and characteristics of low back pain among sitting workers in a Japanese manufacturing company. J Orthop Sci 2015;20:23-30.

16. Croft PR, Papageorgiou AC, Thomas E, et al. Short-term physical risk factors for new episodes of low back pain. Prospective evidence from the South Manchester Back Pain Study. Spine (Phila Pa 1976) 1999;24:1556-61.

17. Leclerc A, Tubach F, Landre MF, et al. Personal and occupational predictors of sciatica in the GAZEL cohort. Occup Med (Lond) 2003;53:384-91.

18. Heliövaara M. Body height, obesity, and risk of herniated lumbar intervertebral disc. Spine (Phila Pa 1976) 1987;12:469-72.

19. Böstman OM. Body mass index and height in patients requiring surgery for lumbar intervertebral disc herniation. Spine (Phila Pa 1976) 1993;18:851-4

20. Coeuret-Pellicer M, Descatha A, Leclerc A, et al. Are tall people at higher risk of low back pain surgery? A discussion on the results of a multipurpose cohort. Arthritis Care Res (Hoboken) 2010;62:125-7.

21. Poussa MS, Heliövaara MM, Seitsamo JT, et al. Anthropometric measurements and growth as predictors of low-back pain: a cohort study of children followed up from the age of 11 to 22 years. Eur Spine J 2005;14:595-8.

22. Karacan I, Aydin T, Sahin Z, et al. Facet angles in lumbar disc herniation: their relation to anthropometric features. Spine (Phila $\mathrm{Pa}$ 1976) 2004;29:1132-6.

23. Gualdi-Russo E, Toselli S, Masotti S, et al. Health, growth and psychosocial adaptation of immigrant children. Eur $J$ Public Health 2014;24(Suppl 1):16-25. 


\section{Correction}

Heuch I, Heuch I, Hagen K, et al. The association between body height and chronic low back pain: a follow-up in the Nord-Trøndelag Health Study. BMJ Open 2015;5: e006983.

In table 1 of this paper, the number of men in the Height $(\mathrm{cm})$ 175-179 group, 'Recurrence among persons with LBP at baseline', is not correct. The correct number is 774 (not 74).

BMJ Open 2015;5:e006983. doi:10.1136/bmjopen-2014-006983corr1

CrossMark 